\title{
Giovanni Dotoli, La Beauté ou le salut du monde
}

\section{Pierangela Adinolfi}

\section{OpenEdition}

\section{Journals}

\section{Edizione digitale}

URL: http://journals.openedition.org/studifrancesi/3912

DOI: 10.4000/studifrancesi.3912

ISSN: 2421-5856

\section{Editore}

Rosenberg \& Sellier

\section{Edizione cartacea}

Data di pubblicazione: 1 décembre 2012

Paginazione: 624

ISSN: 0039-2944

Notizia bibliografica digitale

Pierangela Adinolfi, «Giovanni Dotoli, La Beauté ou le salut du monde», Studi Francesi [Online], 168 (LVI III) | 2012, online dal 30 novembre 2015, consultato il 07 mars 2021. URL: http:// journals.openedition.org/studifrancesi/3912 ; DOl: https://doi.org/10.4000/studifrancesi.3912

Questo documento è stato generato automaticamente il 7 mars 2021.

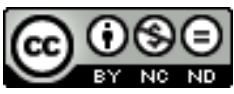

Studi Francesi è distribuita con Licenza Creative Commons Attribuzione - Non commerciale - Non opere derivate 4.0 Internazionale. 


\title{
Giovanni Dotoli, La Beauté ou le salut du monde
}

\author{
Pierangela Adinolfi
}

\section{NOTIZIA}

GIOVANNI DOTOLI, La Beauté ou le salut du monde, Paris, Hermann Éditeurs, 2011, pp. 522.

1 Vero e proprio inno alla Bellezza, salvezza del mondo, il presente studio indaga il significato profondo del concetto di bellezza in tutti i suoi aspetti, legati all'arte, al corpo umano e soprattutto femminile, all'idea di felicità, di natura, di spazio urbanistico ed architettonico, ai concetti di scienza, economia, democrazia, modernità e «art de vivre». Partendo dalla definizione di Charles Chaumont, contenuta nel libro Le secret de la beauté. Essai sur le pouvoir et les contradictions (Paris, Seuil, 1987, p.11): «Apparemment, la beauté est la chose du monde à la fois la plus importante et la plus superflue», Giovanni DOTOLI considera la natura ambigua dell'idea di bellezza, nel tentativo di perseguire una finalità ideale che la vede fulcro di positive energie di rinnovamento. Per affrontare e sconfiggere la crisi occidentale del terzo millennio, è necessario, infatti, secondo l'A., un programma incentrato sui principi e i valori della bellezza. Le facili lamentazioni non servono, s'impone la necessità dell'azione e il ritrovamento del senso della ricerca. La via della bellezza sarà il nuovo punto di partenza verso la rigenerazione ottimistica dell'essere umano e di tutte le sue attività. La beauté assume, pertanto, un ruolo decisivo nella ricostruzione del mondo, nella vita individuale e collettiva.

2 Prendendo il Banquet di Platone come punto di riferimento, secondo il quale dalle «beautés d'ici-bas» è possibile arrivare al «beau surnaturel tout seul» (p.11), l'A. delinea il vastissimo panorama della storia della cultura occidentale e spazia da San Tommaso d'Aquino ad Umberto Eco, passando per Botticelli, Leonardo da Vinci, Molière, Kant, Musset, Stendhal, Baudelaire, Rimbaud, Nietzsche, Marx, Camus e Sartre, solo per citare alcuni esempi. In questo grande intento di sintesi culturale, Dotoli 
traccia il percorso di un «nouvel humanisme» all'insegna della "pensée méridienne» dispensatrice di bellezza: «Il faut recréer une plateforme de dialogue permanent sous l'égide de l'humanisme proposé par la beauté» (p. 427). Solamente attraverso questa via di ricerca della dignità umana e di elevazione spirituale, secondo l'A. sarà possibile per l'uomo il raggiungimento della felicità e della salvezza. Un'ampia Bibliografia e l'Indice dei nomi concludono il volume. 